\title{
Jules Champfleury, Fantaisies
}

\section{Maria Emanuela Raffi}

\section{Q OpenEdition}

\section{Journals}

\section{Edizione digitale}

URL: https://journals.openedition.org/studifrancesi/45335

DOI: 10.4000/studifrancesi.45335

ISSN: 2421-5856

\section{Editore}

Rosenberg \& Sellier

\section{Edizione cartacea}

Data di pubblicazione: 1 août 2021

Paginazione: 394

ISSN: 0039-2944

\section{Notizia bibliografica digitale}

Maria Emanuela Raffi, «Jules Champfleury, Fantaisies», Studi Francesi [Online], 194 (LXV | II) | 2021,

online dal 01 août 2021, consultato il 15 octobre 2022. URL: http://journals.openedition.org/

studifrancesi/45335 ; DOI: https://doi.org/10.4000/studifrancesi.45335

\section{Questo documento è stato generato automaticamente il 15 octobre 2022.}

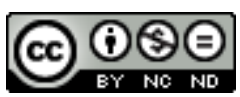

Creative Commons - Attribuzione - Non commerciale - Non opere derivate 4.0 Internazionale - CC BYNC-ND 4.0

https://creativecommons.org/licenses/by-nc-nd/4.0/ 


\title{
Jules Champfleury, Fantaisies
}

\author{
Maria Emanuela Raffi
}

\section{NOTIZIA}

JULES CHAMPfleuRY, Fantaisies, édition établie, présentée et dirigée par M. Lo Feudo, Paris, Champion, 2019, $447 \mathrm{pp}$.

1 Nella «Présentation générale» (pp. 7-31) del volume, che riunisce le tre raccolte pubblicate da Champfleury con la definizione comune di Fantaisies nel 1847, Michela Lo FEUDO, dopo aver tracciato la composita biografia del giornalista/scrittore, ne segue la partecipazione all'acceso dibattito artistico-letterario del tempo, particolarmente a partire dal 1844, anno in cui inizia la sua collaborazione all'“Artiste" e al "CorsaireSatan". Dalle colonne dei due giornali satirici Champfleury si propone fin dall'inizio di «tourner en dérision le milieu auquel il appartient» e si impegna quindi a ritrarre personaggi singolari del mondo artistico o a deridere con particolare vigore le variegate utopie che popolano il panorama culturale di quegli anni, soprattutto quella creata da Charles Fourier, cui dedica numerosi feuilletons fra il '45 e il '46. A questa produzione satirica principale si affiancano, nelle opere giovanili dell'autore, scritti ispirati alle scenette sociali ritratte da Henry Monnier e le pantomime ideate per il «Théâtre des Funambules». Su questo sfondo, le Fantaisies rappresentano nell'analisi della Lo Feudo «une étape stratégique du parcours de légitimation littéraire souhaitée par Champfleury», grazie anche alla mole del lavoro, previsto in quattro volumi - uno per ogni stagione, a partire dalla primavera - e dedicato ad autori decisamente importanti: Victor Hugo, Delacroix, Balzac. Solo tre poiché il quarto volume, Fantaisies d'automne, non è mai uscito. Più volte la curatrice dell'edizione sottolinea il carattere eterogeneo della raccolta e la sua derivazione giornalistica, che tuttavia è anche sintomo di vitalità e di una ricerca «visant à établir des relations originales entre genres, domaines, registres et langages expressifs apparemment différents».

2 Ciascuno dei tre volumi delle Fantaisies è poi presentato con una ricca annotazione, un apparato di variantes e una Introduction, opera di tre diverse autrici. 
3 Sandrine BERTHELOT si occupa dell'edizione di Chien Caillou, Fantaisies d'hiver (pp. 33-170), facendo precedere il testo da alcune considerazioni sulle origini della raccolta, serie di «écrits excentriques» con evidenti legami all'interno della bohème letteraria - in particolare con Nerval, Borel e Janin -, ma altrettanto evidenti prossimità con autori come Heine e Hoffmann. Popolate di «êtres déclassés», le novelle di questo primo volume sono per la Berthelot il singolare prodotto della forte influenza di Balzac, ma al tempo stesso dell'attrazione per una «vie de bohème» alla quale Champfleury guarda con occhio più ironico e grave di quello di Murger.

4 Pauvre trompette, Fantaisies de printemps (pp. 171-325) è presentato e annotato da Michela LO FEUDO, che mette in rilievo l'importante ricostruzione del mondo della 'petite presse' fra il 1845 e il 1846, ispirato in gran parte all'esperienza di Champfleury presso il "Corsaire-Satan". Gli attacchi al critico d'arte della rivista, in difesa della pittura di Delacroix nell'accesso dibattito fra disegno e colore, rappresentano una parte rilevante del volume, nella quale l'A. assegna un ruolo significativo all'amicizia con Auguste Vitu della rivista "La Silhouette". La critica d'arte, sia pure nella consueta declinazione caricaturale, che mette in scena il personaggio di Monsieur Prudhomme come «critiquebourgeois», appare dunque centrale in queste Fantaisies, grazie anche ai riferimenti a Baudelaire, pur lasciando spazio anche alla già sperimentata critica sociale.

5 Aude DÉRUELLE, responsabile del terzo volume - Feu Miette, Fantaisies d'été (pp. 327-428) -, mette l'accento sull'attività di «réécriture» operata da Champfleury al momento di raccogliere i suoi testi giornalistici in un unico insieme. Si interroga inoltre sulla scelta del genere «fantaisie», inteso qui non come semplice antitesi ad un realismo mimetico soffocante, ma come frutto di una «déconnexion entre les faits et le registre choisi pour les traiter». Una scelta che suscita «rires grinçants et regards moqueurs» nei confronti di una realtà di cui, senza tregua, Champfleury «remet en question les catégories». 